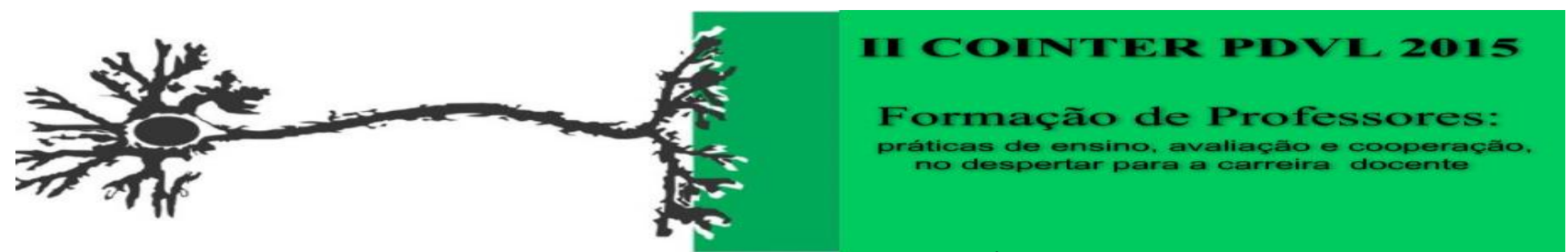

\title{
A CONCEPÇÃO DOS LICENCIANDOS EM QUÍMICA SOBRE OS CONCEITOS DE RECICLAGEM E DESENVOLVIMENTO SUSTENTÁVEL NO CONTEXTO DA SUSTENTABILIDADE
}

\author{
Apresentação: Comunicação Oral
}

\begin{abstract}
Antônio Santana de Souza Júnior ${ }^{1}$; Erica José Bezerra ${ }^{2}$; Diana Guimarães Silva ${ }^{3}$ Magadã Marinho Rocha de Lira ${ }^{4}$
\end{abstract}

\section{Resumo}

Este trabalho objetivou analisar a concepção dos licenciandos de química de um Instituto Federal em Vitória de Santo Antão-Pernambuco sobre os conceitos de reciclagem e desenvolvimento sustentável no contexto da sustentabilidade. Por meio da aplicação de formulário-pergunta colhemos e analisamos as concepções dos alunos sobre estes conceitos. Utilizando-se da metodologia de Análise da Hermenêutica Dialética agrupamos as respostas proferidas pelos sujeitos em três categorias, essas quais emergiram da análise dos conteúdos. A primeira categoria apresenta respostas cujos conteúdos têm forte influência do capitalismo, sendo intitulada como "Materiais sem valor"; já a segunda categoria reuniu um grupo de respostas que têm conteúdos respaldos na epistemologia que fundamenta a Educação Ambiental, sendo denominada como "Reutilização de um material para preservação ambiental"; Por fim, surge uma terceira categoria de respostas, nestas os sujeitos sequer consegue definir os conceitos de modo a fazer alguma ligação com o Meio Ambiente, tendo suas respostas classificadas como "Vaga relação com a natureza". Os resultados obtidos expressaram que os liceciandos em química, mesmo tendo uma disciplina com enfoque ambiental compondo a ementa do seu curso, ainda detêm concepções equivocadas sobre os conceitos de reciclagem e desenvolvimento sustentável. Para o conceito de reciclagem foi registrado um quantitativo de $38,09 \%$ das respostas tidas como corretas, enquanto que $61,9 \%$ equivocadas. Já para o conceito de desenvolvimento sustentável somou-se um quantitativo de $52,38 \%$ das concepções como corretas e $47,61 \%$ como equivocadas. Fato que sinaliza a necessidade de ampliar as discussões sobre as temáticas ambientais nos processos formativos das licenciaturas,

\footnotetext{
${ }^{1}$ Programa de Pós-Graduação em Ensino das Ciências, UFRPE, antoniojr.biologia@yahoo.com.br

${ }^{2}$ Programa de Pós-Graduação em Ensino das Ciências, UFRPE, erica_j.b@hotmail.com

${ }^{3}$ Programa de Pós-Graduação em Ensino das Ciências, UFRPE, dianaguimaraessilva@hotmail.com

${ }^{4}$ Mestre em Educação, Instituto Federal de Educação-IFPE.magada.lira@vitoriaifpe.edu.br
} 
na perspectiva de minimizar tais equívocos nesses cursos, tendo em vista que esses futuros profissionais trabalharão constantemente com esses conceitos em suas práticas docentes.

Palavras-Chave: Reciclagem, Desenvolvimento Sustentável; Ensino de Química.

\section{Introdução}

O século XXI trouxe consigo um desenvolvimento focado em um acúmulo de bens materiais individuais. Este pensamento capitalista ao longo do tempo distorceu a concepção ecológica: "Que um Meio Ambiente ideal para propiciar o bem estar e a qualidade de vida de um ser humano, seria aquele que apresentasse recursos naturais em abundância” (JACOBI, 2011).

Ao longo do tempo o desequilíbrio ambiental impulsionou o desenvolvimento da sociedade contemporânea numa crise de valores ambientais e econômicos. Em resposta a esse cenário, surgem os conceitos - sustentabilidade e desenvolvimento sustentável como alternativa de uma maior educação ambiental para essa sociedade contemporânea.

Sustentabilidade e desenvolvimento sustentável representam a capacidade humana de interagir com o mundo, buscando a conservação do Meio Ambiente e visando o não comprometimento dos recursos naturais e das gerações futuras (CUNHA, 2015). Nesse sentido, entendemos que tais conceitos são complexos, apresentando articulação entre conjuntos de variáveis interdependentes, mas que ao mesmo tempo, devem ter a capacidade de integrar as questões sociais, energéticas, econômicas e ambientais na busca pela conservação ambiental.

Assim, estes conceitos caminham além do enfoque economista do desenvolvimento, pois ressignificam as práticas da sociedade em caráter sócioal e ambiental sobre o econômico. Consideram aspectos vinculados com as deficiências culturais, relações sociais, as múltiplas referências de experiências tradicionais e as vocações locais, todos comportados dentro de práticas educativas (JACOBI, 2011). As quais devem se estruturar dentro da perspectiva transversal que é orientada pelos Parâmetros Curriculares Nacionais, tendo em vistas que esses conceitos são componentes da Educação. Logo, devem ser fixados a partir da estimulação da execução de ações, tendo em vista uma mudança de comportamento e atitudes por meio da construção de concepções conceituais.

Neste contexto social, o qual evidencia uma necessidade de disseminação dos conceituais que permeiem a Educação Ambiental, nota-se que as ações propostas para trabalhar determinados conceitos, como a prática da reciclagem ou desenvolvimento sustentável pode não está sendo 
abordado significativamente nos cursos de licenciatura, o que pode corroborar para a falta de compreensão desses conceitos pelos profissionais da área, professores de química por exemplo.

Para tanto, as perspectivas teóricas sobre a importância das concepções prévias dos estudantes são significativas para traçar a visão dos sujeitos sobre determinados conceitos. Como destaca a Teoria da Aprendizagem Significativa de David Ausubel, a qual procura explicar os mecanismos internos que ocorrem na mente humana com relação ao aprendizado e à estruturação do conhecimento. A essência da teoria enfoca que "o fator isolado mais importante que influencia a aprendizagem é aquilo que o aluno já sabe" (MOREIRA, 1999; p. 152).

Neste sentido, questionamos: quais as concepções dos licenciandos de química sobre os conceitos de reciclagem e desenvolvimento sustentável? Nosso objetivo foi analisar a compreensão dos conceitos de reciclagem e desenvolvimento sustentável dos licenciandos de química de um Instituto Federal em Vitoria de Santo Antão, Pernambuco.

Assim, acreditamos que a partir das ideias que os licenciandos em química trazem consigo sobre a perspectiva ambiental, poderemos traçar seus perfis concepcionais sobre os conceitos de reciclagem e desenvolvimento sustentável, tal como sinalizar a influência de uma disciplina com foco ambiental na emenda do curso sobre essas concepções.

\section{Fundamentação Teórica}

\section{Abordagem de Temas Transversais nos cursos de Licenciatura}

Os Temas Transversais expressam conceitos e valores fundamentais à democracia e à cidadania e correspondem a questões importantes para a atual sociedade brasileira (BOVO, 2004). Sendo assim, optou-se por integrá-los ao currículo, de forma a estarem presentes em todas as áreas, relacionando-os às questões da atualidade (BRASIL, 1998).

Diante da necessidade de interagir com o cotidiano do aprendiz, o processo de formação de professores, também precisa contemplar interações e interdependências, sentidos e necessidades de uma construção coletiva, sem a qual dificilmente se poderá perceber e entender a dimensão complexa do processo educacional, bem como a compreensão da realidade (OLIVEIRA e SANTOS, 2009), atrelado a essas interações se percebe a necessidade da abordagem dos temas transversais no processo formativo de professores desenvolvendo novas propostas para o Ensino de Ciências, diante da contextualização dos fenômenos químicos, físicos e biológicos, contemplando 
uma dimensão que se pretende para a compreensão da vida cotidiana (OLIVEIRA e SANTOS, 2009).

Correlacionando os cursos de licenciatura aos Temas Transversais, a produção de conhecimento deve necessariamente contemplar as inter-relações do meio natural com o social, incluindo a análise dos determinantes do processo, o papel dos diversos atores envolvidos e as formas de organização social que aumentam o poder das ações alternativas de um novo desenvolvimento (JACOBI, 2003). Dessa forma, um dos Temas Transversais que apresentam destaque, não só nos cursos de Ciências Biológicas, como também nos cursos de Licenciatura em Química é a Educação Ambiental.

A sociedade atual está cada vez mais consciente da necessidade de construir um futuro sustentável, sendo discutido o significado de sustentabilidade e as características que lhe estão subjacentes (FREIRE, 2007). Ainda segundo Freire (2007), as orientações para o ensino dessa temática e a formação de professores implica perspectivar uma nova orientação para a prática letiva, enfatizando situações de aprendizagem experienciais, colaborativas e ativas dirigidas para a resolução de problemas aos níveis local, regional e global.

\section{O Ensino de Química e a Educação Ambiental}

A Química é uma ciência construída histórica e socialmente; e, portanto, imbuída de valores, aspectos políticos e econômicos (BORGES, 2007). Ela está relacionada a tudo o que o homem faz e necessita, desde o seu alimento ou remédios, até a forma de lidar com as novas tecnologias (BRASIL, 1999). Para Santos (2014), a química, consiste em uma ciência dedicada em produzir benefícios e qualidade de vida ao homem, e que alargou suas fronteiras de maneira que se tornou impossível delimitar seus campos de atuação.

Diante dessa amplitude, podemos dizer que o Ensino de química está relacionado com a vida, e essa afirmação fica notória na fala de muitos professores de química, ao afirmarem: "A química está em tudo que nos rodeia", (LUCA, s/ ano). Dessa maneira, torna-se fundamental, que o ensino de química leve a sociedade a ter conhecimentos necessários que a direcionem para um posicionamento mais adequado para com a natureza, visto que, a relação homem-natureza deve ser vistas como um único, e não como partes separadas, e esta visão só serão construídas através da educação (BRASIL, 1999). 
Segundo BRASIL (1999), a educação deve, portanto, favorecer ao indivíduo a análise crítica sobre seu lugar no mundo e considerar o significado de desenvolvimento sustentável e as formas de manejá-lo, construindo assim, uma população informada, ativa e preocupada. Com isso, Santos (2014), afirma que é notória a preocupação global no que se referem às questões ambientais, nas mais diversas áreas do conhecimento e devido ao caráter interdisciplinar e complexo dessa temática, evoca a contribuição das ciências da natureza, tais como a química.

Diante dessa preocupação global, o ensino de química, tem focado nas questões ambientais, relacionando os conteúdos de química com a Educação ambiental, cujos objetivos consistem em oferecer subsídios elementares para que os estudantes sejam capazes de participar das decisões tomadas por nossos governantes, tornando-se cidadãos críticos, ativos e participativos, como também, cidadãos preocupados, consciente, e que sejam capazes de manter uma relação homemnatureza de forma sustentável. (SANTOS, 2014).

\section{Aprendizagem Significativa de Ausubel}

A Teoria da Aprendizagem Significativa, proposta nos anos 60, estabelece uma relação entre o conhecimento já adquirido pelo aluno a um novo conhecimento que deve ser interiorizado em sua estrutura cognitiva (AUSUBEL, NOVAK e HANESIAN, 1980, apud RODRIGUES, 2012), consistindo num processo pelo qual uma nova informação recebida pelo sujeito interage com uma estrutura de conhecimento específica orientada por conceitos relevantes, os subsunçores, e dessa interação entre os conhecimentos, surge a apredizagem significativa (ALEGRO2008).

Segundo Ausubel, Novak e Hanesian (1980, apud FONTANINI, s/ ano), afirmam que existem três condições para que ocorra aprendizagem significativa, tais como: 1- O material usado no ambiente de ensino e aprendizagem deve ser potencialmente significativo; 2- $\mathrm{O}$ aluno precisa possuir subsunçores (conhecimentos prévios), com os quais o novo conhecimento se relaciona de forma não arbitrária e substantiva; 3- $\mathrm{O}$ aluno precisa querer relacionar de forma não arbitraria e não literal o novo conteúdo com conteúdo já existente, ou seja, ele precisa estar predisposto para aprender.

De acordo com Rodrigues (2012), para que o ocorra uma aprendizagem significativa é preciso entender o processo de modificação do conhecimento em uma reflexão específica de situações de aprendizagem. Os indivíduos apresentam uma organização cognitiva interna baseada 
em conhecimentos de caráter conceitual, sendo que sua complexidade depende muito mais das relações que esses conceitos estabelecem entre si do que do número deles.

\section{Metodologia}

Este estudo teve natureza qualitativa e quantitativa, cujo universo amostral foi de 21 licenciandos em química de um Instituto Federal localizado em Vitória de Santo Antão-PE, esses dotados de formação básica regular e alguns acrescidos de formação técnica ou profissionalizante. Ressaltamos que esses sujeitos são residentes das diversas cidades do interior da zona da mata de Pernambuco circunvizinhas da cidade sede do campus.

A coleta de dados foi oportunizada por meio de um questionário semiestruturado nos seguintes termos:

\section{1- "O que você entende por RECICLAGEM?" \\ 2-“O que você entende por DESENVOLVIMENTO SUSTENTÁVEL?"}

Para tanto, analisamos as concepções dos alunos e agrupamos as respostas dissertativas em três grupos ou categorias distintas de acordo Minayo (2004), seguindo o método da Análise Hermenêutica-Dialética (AHD), o qual consiste na análise do conteúdo.

O método hermenêutico-dialético é o mais capaz de dar conta de uma interpretação aproximada da realidade. Essa metodologia coloca a fala em seu contexto para entendê-la a partir do seu interior e no campo da especificidade histórica e totalizante, em que é produzida. (MINAYO, 2004, P. 231).

Assim, ao utilizarmos a AHD como meio de análise dos conteúdos dos discursos proferidos pelos licenciandos, encontramos os elementos que nos permite promover o desenvolvimento de categorias, as quais nos possibilita agrupar e entender as visões sobre as experiências e concepções desses sujeitos com os conceitos e o campo ambiental.

\section{Resultados e Discussão}

Análise Hermenêutica Dialética dos discursos proferidos pelos sujeitos possibilitou a formação de três categorias ou grupos concepcionais, os quais são apresentados abaixo: 
$1^{\circ}$ grupo: "Materiais sem valor"

$2^{\circ}$ grupo: "Reutilização de um material para preservação ambiental"

3 grupo: "Vaga relação com a natureza"

\begin{tabular}{|c|c|c|c|}
\hline Perguntas & $\begin{array}{c}\text { Concepção 1: } \\
\text { Materiais sem valor }\end{array}$ & $\begin{array}{c}\text { Concepção 2: } \\
\text { Reutilização de material } \\
\text { para preservação } \\
\text { ambiental }\end{array}$ & $\begin{array}{c}\text { Concepção 3: } \\
\text { Vaga relação com a } \\
\text { natureza }\end{array}$ \\
\hline $\begin{array}{l}\text { O que VOCÊ entende por } \\
\text { RECICLAGEM? }\end{array}$ & $\begin{array}{l}6 \text { ou } 28,57 \% \text { dos } \\
\text { entrevistados }\end{array}$ & $\begin{array}{l}8 \text { ou } 38,09 \% \text { dos } \\
\text { entrevistados }\end{array}$ & $\begin{array}{c}7 \text { ou } 33,33 \% \text { dos } \\
\text { entrevistados }\end{array}$ \\
\hline $\begin{array}{l}\text { O que VOCÊ entende por } \\
\text { DESENVOLVIMENTO } \\
\text { SUSTENTÁVEL? }\end{array}$ & $\begin{array}{l}6 \text { ou } 28,57 \% \text { dos } \\
\text { entrevistados }\end{array}$ & $\begin{array}{l}11 \text { ou } 52,38 \% \text { dos } \\
\text { entrevistados }\end{array}$ & $\begin{array}{l}4 \text { ou } 19,04 \% \text { dos } \\
\text { entrevistados }\end{array}$ \\
\hline
\end{tabular}

No quadro abaixo apresentamos os quantitativos em porcentagem das respostas corretas e equivocadas dos estudantes sobre os conceitos de Reciclagem e Reaproveitamento sustentável no contexto da sustentabilidade.

Quadro 1: As concepções sobre os conceitos de RECICLAGEM e DESENVOLVIMENTO SUSTENTÁVEL. Fonte: Os Autores a partir dos sujeitos entrevistados.

No quadro acima, notamos que o grupo (1), define os conceitos de reciclagem e reaproveitamento sustentável como "Materiais sem valor algum (lixo) voltado a ter um valor econômico", uma concepção estritamente capitalista acerca dos conceitos em questão, uma visão equivocada que se estabelece fortemente entre os sujeitos.

Já o grupo (2), definiu os conceitos como "Reutilização de um material para produzir outro aumentando sua vida útil, na perspectiva de preservar o Meio Ambiente".

Ao passo em que quando analisamos o grupo (3), notamos que esse conceituou os conceitos como "Algo haver com a natureza, mas não se sabe definir efetivamente o que são de fato". Ou seja, uma concepção totalmente desarticulada de uma epistemologia conceitual, caminhando assim 
como o grupo (1), para interpretações conceituais equivocadas.

Neste sentido, é importante que os licenciandos apresentem uma ideia mais consistente sobre os conceitos, uma vez que os Parâmetros Curriculares Nacionais ressaltam a importância das discussões sobre os ciclos da natureza, da reciclagem, do lixo, entre outros, para compreensão sobre o relevante e contemporâneo conceito de Meio Ambiente no contextos formativos e sociais (BRASIL, 2000).

Balizado por essas perspectivas traçadas até o momento, percebemos que as concepções que se expressam na síntese do grupo (2), apontam as concepções de reciclagem e desenvolvimento sustentável mais próximo do contexto científico.

Neste sentido, somando os valores das porcentagens referentes aos números de licenciandos com concepções tidas como corretas e equivocadas sobre os conceitos transversais em questão, obtivemos o resultado que se apresenta a seguir (Gráfico 1).

Gráfico 1: As concepções corretas e equivocadas dos alunos sobre os conceitos transversais: RECICLAGEM e REAPROVEITAMENTO SUSTENTÁVEL. Fonte: Os Autores a partir dos sujeitos entrevistados.

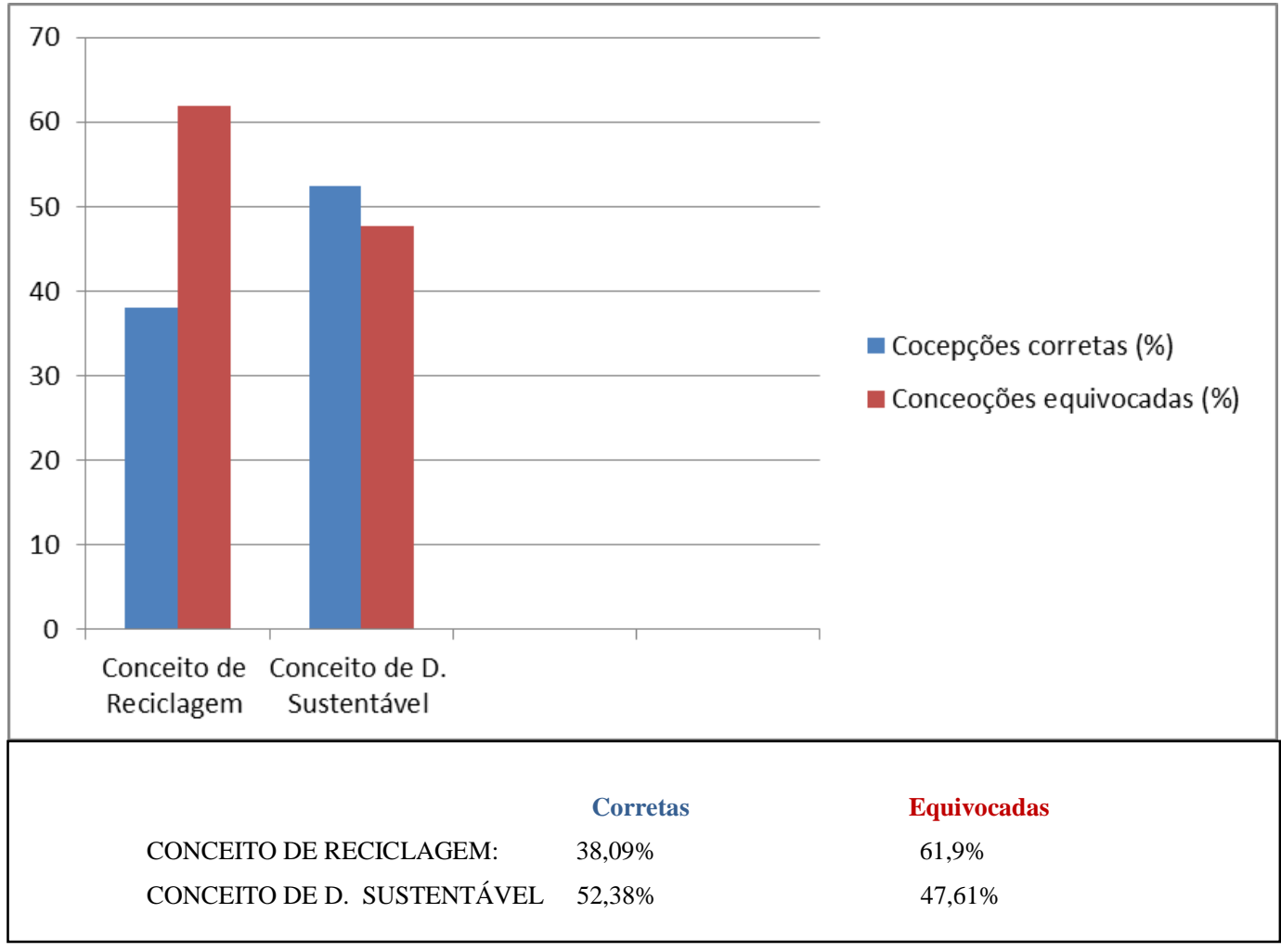


Com a soma das porcentagens numéricas das concepções dos sujeitos, obtemos um quantitativo de $38,09 \%$ das concepções como corretas, ao passo em que $61,9 \%$ como equivocadas para o conceito de RECICLAGEM, enquanto que em se tratando do conceito de DESENVOLVIMENTO SUSTENTÁVEL foram 52,38\% corretas para 47,61\% equivocadas.

Assim, o gráfico expressa um percentual significativo de licenciandos que apresentaram concepções equivocadas sobre os conceitos, o que pode discorre possivelmente sobre pouca experiência sobre o conteúdo e que pode ser modificado numa abordagem em disciplinas que evoquem a perspectiva ambiental no ensino superior, mas, sobretudo com a promoção de eventos acadêmicos que discutam com mais frequência essa temática dentro do processo formativo.

Para Neves (2006), um número de ideias equivocadas pelos licenciandos é reproduzido irrefletidamente a partir de vivencias do cotidiano. Ou seja, é possível que exista uma fragilidade na formação educacional que pode não ter contemplado ao individuo experiências que o permitissem construí conceitos mais expressivos e um discurso mais pautado nas perspectivas cientificas, ou seja, libertas de um senso comum.

\section{Conclusões}

O fato de se ter uma significativa porcentagem de concepções equivocadas sobre os conceitos transversais reciclagem e desenvolvimento sustentável em turmas de licenciaturas de química, nos permitiram considerar a importância pela qual esses conceitos devem ser trabalhados dentro das Instituições de Ensino Superior.

Tendo em vista que as demandas contemporâneas que são impostas a educação redirecionaram a função que esta tem dentro da sociedade, de modo que o foco atual fixa na formação critica social do aluno. E nesse contexto, os Parâmetros Curriculares Nacionais sinalizam dentre outras temáticas de relevância social, a importância da Educação Ambiental. Logo, os processos de formação de professores devem se preocupar com a promoção dos discursos que contemplem os conceitos dessa temática, na perspectiva de aprimorar as concepções desses licenciandos, uma vez que esses vão de qualquer formar, ter que incorporar esses temas constantemente em suas práticas docente.

Muitos dos licenciando ainda possuem concepções arraigadas no senso comum que acabam direcionadas a condição equivocada de compreensão e utilização desses conceitos, mesmo existindo uma disciplina com foco ambiental na ementa do seu curso. Assim, entendemos que as Universidades e Institutos de Ensino Superior devem estimular as atividades sobre a temática de forma mais latente, viabilizando ações para minimizar possíveis problemas conceituais nos saberes 
de formação profissional de seus licenciandos, orientando uma formação baseada na perspectiva de se desenvolver uma prática docente mais aperfeiçoada na capacidade de formar cidadãos e cidadãs ambientalmente mais conscientes e sustentáveis.

\section{Referências}

ALEGRO, R. C. Conhecimento prévio e Aprendizagem Significativa de conceitos históricos no Ensino Médio. Marília, São Paulo 2008.

BRASIL, Secretaria de Educação Fundamental. Parâmetros Curriculares Nacionais: Ciências da Natureza, Matemática e suas Tecnologias. Brasília: MEC/SEF, 2000.

BRASIL. Parâmetros Curriculares Nacionais: $3^{\text {o }}$ e $4^{\mathbf{0}}$ Ciclos: apresentação dos temas transversais. Secretaria de Educação Fundamental. Brasília, DF: MEC/SEF, 1998.

BRASIL. Lei 9.795, de 27 de abril de 1999. Institui a Política Nacional de Educação Ambiental. Brasília: Diário Oficial da União, 28 de abril de 1999.

BORGES, R.M.R. Em debate: cientificidade e educação em ciência. 2a edição revista e aplicada. Porto Alegre: EDIPUCRS, 2007.

BOVO, M.C. Interdisciplinaridade e Transversalidade como dimensões da ação pedagógica. Revista Urutágua, Paraná, n.7, Ago/Set/Out/Nov 2004.

CUNHA, F. L. S. J. Desenvolvimento, agricultura e sustentabilidade. Disponível em http://www.cori.rei.unicamp.br. Acesso em 10/05/2015.

FREIRE, A. N. Educação para a Sustentabilidade: Implicações para o Currículo Escolar e para a Formação de Professores. Pesquisa em Educação Ambiental, vol. 2, n. 1 - pp. 141-154, 2007.

FONTANINI, M. L. C. Mapas Conceituais em Atividades de Modelagem Matemática. S/ ano.

JACOBI, P. Educação ambiental, cidadania e sustentabilidade. Cadernos de Pesquisa, São Paulo, n. 118, p. 189-205 março 2003.

LUCA, A. G. O Ensino de Química e algumas considerações. S/ ano.

MINAYO, M. C. S. Pesquisa social: teoria, método e criatividade. 23 Ed. Petrópolis, RJ: Vozes, 2004.

MOREIRA, M. A. Teorias de Aprendizagem. São Paulo: EPU, 1999. 
NEVES, R. F. A Interação do Ciclo da Experiência de Kelly com o Círculo HermenêuticoDialético, para a Construção de Conceitos de Biologia. Brasil, 2006. Dissertação (Mestrado em Ensino das Ciências). Universidade Federal Rural de Pernambuco.

OLIVEIRA, M. I.; SANTOS, E. C. A prática da transversalidade na formação de professores para o ensino de ciências, nas universidades públicas da cidade de Manaus. VII ENPEC: Encontro Nacional de Pesquisa em Ensino de Ciências, Florianópolis, 2009.

RODRIGUES, R. F. O uso de modelagens representativas como estratégia didática no ensino da genética: um estudo de caso. Experiências em Ensino de Ciências V.7, No. 2, 2012.

SANTOS, K. et al. Química e Educação Ambiental: Uma Experiência no Ensino Superior. Vol. 36, $\mathrm{N}^{\circ} 2$, p. 119-125, MAIO 2014. 